\title{
Um coro harmonioso: alteridade e ethos abyayalense no pensamento ambiental latino-americano
}

\author{
A harmonious chorus: Abyayalan alterity and ethos in Latin American \\ environmental thinking
}

Resenha da obra: ECHEVERRI, Ana Patricia Noguera de. (org). Voces del pensamiento ambiental: tensiones criticas entre desarrollo y abya yala. Bogotá: Editorial Universidad Nacional de Colombia, 2016.

\section{Clayton Peron Franco de Godoy'}

A coletânea reúne ensaios de integrantes do Grupo de Investigación en Pensamiento Ambiental de la Universidad Nacional de Colombia - Sede Manizales, cuja proposta institucional é construir um pensamento ambiental crítico a partir de perspectivas não eurocêntricas, tendo como fundamento epistemológico concepções de cunho hermenêutico.

Organizado sob a responsabilidade de sua coordenadora, a colombiana Ana Patricia Noguera de Echeverri, o livro reúne artigos de autores provenientes das mais diversas formações: filosofia, biologia, administração, ciências sociais e ciências agrárias. Essa transdisciplinaridade, que caracteriza tanto a obra como o grupo de pesquisa, é perpassada por algumas referências teóricas comuns: o colombiano Carlos Augusto Ángel Maya, os chilenos Humberto Maturana e Francisco Varela, além dos europeus Fritjof Capra, Martin Heidegger, Michel Serres, Jacques Derrida, Gilles Deleuze e Michel Foucault.

Por meio desse arcabouço conceitual, a obra inscreve-se na perspectiva da ecologia política latino-americana, cujas propostas podem ser sumariadas em três eixos: a) a descolonização do pensamento teórico, com a proposição de abordagens embasadas na experiência latino-americana que agenciem seletiva e criticamente, de maneira dialógica, as formulações provenientes dos países centrais do sistema capitalista; b) a construção de

\footnotetext{
1 Doutor em sociologia pela Universidade de São Paulo (USP), São Paulo, Brasil. E-mail: claytonperon@gmail.com.
} 
uma proposta epistemológica que absorva a dimensão territorial; c) o empenho em construir alternativas teóricas e práticas, simultaneamente políticas e éticas, que permitam ultrapassar os impasses e reveses produzidos pelas noções hegemônicas de desenvolvimento e de modernização, com o fito de promover a reapropriação dos territórios e a reintegração entre grupos sociais e ecossistemas.

O livro foi estruturado em um formato que alude a uma composição musical. É composto por um prelúdio e seis "movimentos", cada um sob responsabilidade de um autor. Mantendo essa metáfora, pode-se dizer que, embora os solos vocais se sucedam, existe um temário que os harmoniza, explicitado no prelúdio assinado pela organizadora da coletânea: a análise do conceito ocidental de desenvolvimento, a avaliação de seus efeitos sobre os diferentes territórios e a reflexão sobre alternativas possiveis para estruturar as relações entre culturas e ecossistemas, superando a dualidade entre ser humano e natureza. Os seis artigos podem ser lidos a partir de três pares temáticos: os dois primeiros a respeito do desenvolvimento e suas alternativas conceituais, o terceiro e quarto sobre produção do conhecimento e educação ambiental e os dois últimos sobre administração e organização empresarial

O primeiro movimento, " Paisajes del desarrollo: desilusión, disolución, devastación y desolación", de autoria do filósofo e cientista social Jaime Alberto Pineda Muñoz, explora os imaginários e conceitos acerca do desenvolvimento. Tratando-o como um slogan, dedica-se à sua desconstrução, à maneira derridariana. Revela os significados associados ao discurso sobre o desenvolvimento fossilizados na linguagem: crescimento, melhoria, progresso, direção, desdobramento enquanto extensão do sempre o mesmo sobre um plano, expansão de um modelo. Extrai dessas acepções as promessas malfadadas da utopia da modernidade, que conduzem à instauração de modelos e politicas de desenvolvimento guiadas unicamente pela razão instrumental, sintetizadoras da confiança da realização do logos. Ancorado em Foucault, opõe a essa utopia do projeto do desenvolvimento uma distopia de sua efetividade: modelo enquanto capacidade de moldar, inscrito em paisagens e corpos, submetendo ambos a formatações estranhas 
à sua natureza. Entender o desenvolvimento nesse registro franqueia o acesso aos seus verdadeiros enunciadores e maquinários de produção simbólica: as corporações globais da economia mundial.

As vias de acesso que põem a nu a distopia implicada no discurso do desenvolvimento são os "discursos marginalizados" dos povos originários e das manifestações artísticas. Atento a essas vozes, Muñoz desvela quatro paisagens do desenvolvimento: desilusão, dissolução, devastação e desolação. Marcadas por uma combinação entre racionalidade política, racionalidade econômica e racionalidade técnica, o desenvolvimento, em quaisquer dessas paisagens, surge divorciado do mundo ético-político. Mira a geografia das terras com as lentes da rentabilidade e avalia as práticas coletivistas como obstáculos ao pleno desenrolar da economia de mercado. Frente a isso, é necessária a constante interrogação sobre a crise ambiental, expressão parcial do que, é, na verdade, uma crise civilizacional.

"Paisajes del desarrollo: evocación, rememoración, conmemoración y reencantamiento" é o título do segundo movimento, sob responsabilidade da filósofa Ana Patricia Noguera de Echeverri. A autora aprofunda as intuições de Ángel Maya, que nos anos 1990 caracterizou o ambiente como fruto das interações entre culturas e ecossistemas, descartando a interpretação corrente de que se tratava do conjunto de recursos naturais disponíveis para extração, o que permite apreender analiticamente a dialética entre sociedade e natureza. Com a finalidade de reconstituir a trama desse "tecido simbólicobiótico" do ambiente, sublinha a necessidade do pensamento ambiental deter-se analiticamente nos diversos modos do "habitar a terra", contrastantes com a cisão entre vida e natureza operada pela objetificação da terra no modelo de economia capitalista. Nesse sentido, propõe que o pensamento ambiental qualifique-se como um "geopensamento", incorporando os diversos modos existenciais de territorialidade das comunidades latino-americanas.

Sua aproximação das vozes das populações originárias do continente se faz por dois caminhos. O primeiro é pelo reconhecimento das nomenclaturas e classificações nativas: Abya yala, vocábulo da etnia cuna, habitante das terras da Costa Rica, Panamá e Colômbia, é simultaneamente 
o nome dado ao continente latino-americano ("terra generosa") e um ethos ("o bem viver"). De maneira similar,o Sumak Kawsay dos povos indígenas equatorianos é o equivalente em quíchua para "bem viver". Já o termo kaklavetzá dos cabécar costa-riquenhos refere-se ao ambiente ou a um ecossistema, ou seja, fauna, flora, meio físico e pessoas incluídos em um mesmo território, enquanto que Btsanamama é a "mãe terra" entre os kamentsa colombianos. O segundo modo de aproximação das categorias nativas é feito por intermédio da música popular, analisando canções de compositores de vários países, como María Elena Walsh, Alberto Evaristo Ginastera, Yamandú Costa, Astor Piazzolla e Silvestre Revueltas. Na convergência desses dois caminhos, Echeverri encontra a cultura em seu sentido forte, como cultivo de si e da terra, em que as comunidades produzem e reproduzem o seu modo de habitar, entendendo-se como parte da terra, integrantes do ambiente. Em contraponto às paisagens lúgubres que caracterizaram o primeiro movimento, próprias do desenvolvimento, a autora introduz quatro outras paisagens, vibrantes, que extraem sua positividade desses modos de vida holísticos: evocação, rememoração, comemoração e reencantamento.

O terceiro movimento, intitulado "Relación ser humano-naturaleza: del ecocidio a la convivencialidad", é assinado pelo biólogo e cientista agrário Giovannie Soto Torres. Inaugura o segundo par temático, a respeito das relações entre conhecimento e educação ambiental. O artigo aborda três tipos de relação com a natureza: o conhecer, o ser e o fazer. A discussão epistemológica contrapõe o essencialismo, que postula a separação entre sujeito e objeto e a ocorrência do conhecimento progressivo da realidade, ao construtivismo, que advoga a indissociabilidade entre sujeito e objeto e considera a produção do conhecimento contextual e dependente da experiência. No tocante à relação entre ser e natureza, o autor embasa sua perspectiva em Maturana e Varela, afirmando a autonomia dos organismos vivos em sua característica essencial de possuir como padrão dinâmico de organização a autopoiesis, isto é, a autorreprodução. Essa fundamentação importa na medida em que uma alteração na autopoiesis produz uma alteração na relação do sistema vivo com o ambiente. Transportada para a 
esfera das sociedades humanas, essa concepção traz implicações para as alternativas à disposição para a modificação das relações entre o fazer e o ambiente. Soto-Torres contrapõe dois padrões desse tipo de relação. O primeiro é o ecocídio, definido como uma ação destrutiva do ser humano em relação à natureza. O segundo é a convencionalidade, na qual a natureza é tanto o princípio como a finalidade de relações harmoniosas entre o ser humano, a sociedade e as técnicas. Assumindo uma concepção de sociedade como rede de relações, pressupõe que mudanças nas pessoas conduzem a mudanças nos grupos sociais. Por conseguinte, o processo educativo tornase fundamental para a construção de um padrão de convencionalidade nos âmbitos do conhecer, do ser e do fazer. Ao lado desse processo educativo, outros valores a serem fomentados socialmente seriam a bioeconomia e a ferramenta convivencial, compreendida como conjunto de instrumentos e tecnologias ecofilicas.

Em "Entre el modelo de la eficacia del desarrollo y el devenir pensamiento educativo ambiental", o quarto movimento é conduzido pelo biólogo e educador ambiental Carlos Alberto Chacón Ramírez. Sua abordagem sobre a educação ambiental oferece um deslocamento da perspectiva antropocêntrica, responsável tanto pela reprodução do saber instrumental como pela noção de sustentabilidade ambiental nos marcos do capitalismo. Em vez de uma educação ambiental, propõe uma "ambientalização da educação", ancorada no conceito deleuziano de rizoma, capaz de romper os agenciamentos educacionais disciplinares e tecer redes, o que estaria em consonância com a estrutura do próprio mundo da vida. Nessa concepção, o lugar ocupa o centro, como plêiade de sentidos e processos naturais, espaço vivido e experienciado, e não mais um espaço como território, conquistado, submetido, universalizável porque esvaziado de suas práticas, tal como na educação ambiental comum. Essa alternativa é na verdade uma ruptura: pensar radicalmente as maneiras diferentes de habitar a terra é adotar um "ethos abyayalense", ou seja, subverter a ordem pela valorização dos saberes subordinados e marginalizados. Em suma, uma educação baseada na perspectiva das populações originárias, em que a convivência com os outros e com a natureza adquire posição central. 
O quinto movimento, intitulado "Paisajes del desarrollo: la organización empresarial en tiempos de crisis ambiental", do administrador e sociólogo Andrés Arias Pineda, investiga o tensões entre as práticas administrativas e teorias organizacionais e a crise ambiental. $O$ artigo reconstrói as trajetórias desse relacionamento, identificando a prevalência de uma visão burocrática e economicista das organizações empresariais, pautada pelos critérios da eficiência e da eficácia. Paralelamente, o pensamento econômico, em suas vertentes clássica, keynesiana ou mesmo cepalina, assumiu a sinonímia entre desenvolvimento econômico e industrialização. Como corolário, a empresa foi identificada simultaneamente como célula e centro de gravidade da sociedade moderna, institucional social apta a oferecer as soluções necessárias para a reprodução social. Ocorre que, com isso, a sociedade moderna reduziu a sua própria racionalidade ao modelo da racionalidade burocrático-administrativa orientada para o desenvolvimento econômico. Para Pineda, a prevalência dos critérios das organizações empresariais sobre critérios ecológicos ou sociais está no cerne da crise ambiental. Seria necessário, segundo o autor, redefinir tais critérios, requalificando a estrutura e o papel das empresas na sociedade. Para essa tarefa, a noção de sustentabilidade é insuficiente, pois repõe o mito desenvolvimentista e a do crescimento econômico indefinido. A alternativa é a reestruturação das teorias organizacionais e das práticas administrativas com base no pensamento complexo ambiental, baseado nas ideias de Capra, Ángel Maya, Varela e Morin. Sob essa ótica, a empresa deve reconhecer-se e ser reconhecida como empresa viva, organizando-se em rede e reunindo quatro elementos fundamentais para sua ecopoiesis: aprendizagem, pessoa, ecologia e evolução.

Foi escolhido para encerrar a coletânea, o artigo "La epistemología en la comprensión de las relaciones entre administración y desarrollo", elaborado pelo administrador Samuel López. Retomando os argumentos do ensaio anterior a respeito da centralidade da empresa e do desenvolvimento econômico na sociedade moderna, López aborda o problema de uma ótica filosófica. Desse ponto de vista, as teorias e práticas administrativas, longe de possuírem o caráter científico e técnico apregoado por sua 
autorrepresentação, são ciências sociais subordinadas eticamente ao mundo da vida. Assim, sua referência principal são os problemas humanos, e não as questões técnicas relativas à eficiência e eficácia econômicas. Assumir essa visão requer uma ampliação tanto da noção de administração como de desenvolvimento.

Em seu conjunto, a polifonia dessa obra coletiva oferece contestações instigantes para noções arraigadas no campo do desenvolvimento e do pensamento e da educação ambiental, nomeadamente aquelas relativas à responsabilidade socioambiental empresarial e ecocapitalismo. Ainda que suas respostas não sejam definitivas, correspondem a pontos de partida para diálogos proveitosos e transdisciplinares. A título de exemplo, pode-se indicar seu avanço no debate a respeito dos limites concretos de concepções de desenvolvimento sustentável em moldes capitalistas, principalmente em sociedades da periferia do sistema global, informadas por outras concepções ser e de estar no mundo. Uma provocação final, que certamente a leitura da obra suscita: quais os limites para a construção de uma relação simétrica entre a intenção descolonizadora dos autores e o seu recurso simultâneo a autores europeus? Ou, mais incisivamente, como dar o passo decisivo rumo a concepções filosóficas, ordenamentos discursivos e práticas socioeconômicas radicalmente ancorados em pressupostos epistemológicos abyayalenses, sem recusar mas simultaneamente sem capitular diante das referências e formas de dominação ocidentais? Esse é o horizonte que a polifonia dos autores desafia o leitor a tentar cruzar.

\section{Referências bibliográficas:}

CAPRA, Fritjof. (2006). A teia da vida. Una nova compreensão científica dos sistemas vivos. São Paulo: Cultrix, 1997.

DEleuZE, Gilles e GUATTARI, Félix. Mil Platôs. Capitalismo e Esquizofrenia. Rio de Janeiro: Editora 34, 1995-1997.

ECHEVERRI, Ana Patricia Noguera de. (org). Voces del pensamiento ambiental: tensiones críticas entre desarrollo y abya yala. Bogotá: Editorial Universidad Nacional de Colombia, 2016.

FOUCAULT, Michel. As palavras e as coisas - uma arqueologia das ciências humanas. São Paulo: Martins Fontes, 2016. 
MATURANA, Humberto. A árvore do conhecimento: as bases biológicas da compreensão humana. São Paulo: Palas Athena, 2001.

MATURANA,, Humberto ; VARELA, Francisco J. De máquinas y seres vivos. Autopoiesis: la organización de lo vivo. Buenos Aires: Editorial Universitaria/Lumen, 2004.

MAYA, Ángel. La fragilidad ambiental de la cultura. Bogotá: Universidad Nacional de Colombia- IDEA , 1995.

MAYA, Ángel. La trama de la vida. Bases ecológicas del pensamiento ambiental. Cuadernos Ambientales, 1. Bogotá: Universidad Nacional de Colombia- IDEA / Ministerio de Educación Nacional, 1993.

SERRES, Michel. O contrato natural. São Paulo: Instituto Piaget, 1994. 